\title{
Seed Priming With an Animal-derived Protein Hydrolysate Improves Drought Tolerance of Tomato Seeds by Enhancing Reserve Mobilization, Osmotic Adjustment, and Antioxidant Mechanism
}

\author{
Weixuan Wang \\ Qingdao Agricultural University \\ Chenglong Zhang \\ Qingdao Agricultural University \\ Wenlong Zheng \\ Qingdao Agricultural University \\ Haofeng Lv \\ Qingdao Agricultural University \\ Weiwei Zhou ( $\sim$ qnzhouww@qau.edu.cn ) \\ Qingdao Agricultural University \\ Bin Liang \\ Qingdao Agricultural University \\ Junliang Li \\ Qingdao Agricultural University
}

\section{Research Article}

Keywords: biostimulant, drought stress, reserve mobilization, antioxidant stress, Solanum lycopersicum L

Posted Date: September 30th, 2021

DOI: https://doi.org/10.21203/rs.3.rs-939786/v1

License: (c) (i) This work is licensed under a Creative Commons Attribution 4.0 International License.

Read Full License 


\section{Abstract}

Purpose Protein hydrolysates obtained from agro-industrial byproducts have received much attentions due to their positive roles in regulating plant responses to environmental stresses. However, little is known about the roles of animal protein hydrolysates in mediating seed drought tolerance and the underlying mechanism. Here, the effects of seed priming with pig blood protein hydrolysates (PP) on tomato seed germination and seedling growth under drought stress were investigated.

Methods Tomato seeds were soaked with different concentrations of PP solutions for $24 \mathrm{~h}$, and then transferred to filter paper moistened with distilled water or 10\% PEG-6000 solution in Petri dish. The germination traits, seeding growth, reserve mobilization, osmolytes, and antioxidant system were determined.

Results PP priming effectively alleviated the reduction in seed germination traits, resulting in improved tomato seedling growth under drought stress. PP priming enhanced amylase and sucrose synthase activities, soluble sugar, soluble protein, and free amino acid levels, thereby promoting reserve mobilization in seeds. Moreover, PP priming also reduces osmotic toxicity by increasing the accumulation of proline, soluble protein, and soluble sugar. Drought stress substantially enhanced the production of ROS and subsequent increases in MDA and Evans blue uptake, which were significantly alleviated after PP priming by improving the activities of SOD, POD, and CAT, and non-enzymatic antioxidants.

Conclusion PP priming is a feasible method for improving tomato seed germination and seedling growth under drought stress by enhancing reserve mobilization, osmolyte accumulation, and antioxidant systems.

\section{Introduction}

Crops under natural conditions face various environmental constraints, including drought, salinity, temperature, and heavy metals (Anderson et al., 2020; Bai et al., 2019; Lei et al., 2021). Annually, these abiotic stresses cause a reduction of approximately $70 \%$ in the potential crop yields worldwide (Trevisan et al., 2019; Razi and Muneer, 2021). Among these environmental constraints, drought stress is a critical problem in arid/semi-arid regions, affecting approximately $33 \%$ of the land area, resulting in a loss of approximately 29 billion USD across the world during 2005 to 2015 (Marthandan et al., 2020; Trenberth et al., 2013). It is estimated that the intensity and frequency of drought stress will increase, especially with the increase in irrigated areas, climate change, and population growth (Trenberth et al., 2013; BaileySerres et al., 2012). Therefore, it is crucial to develop feasible strategies to improve the performance and yield of crops under drought stress in the future.

Germination and seedling stages are considered to be the initial and critical periods in a plant life cycle, and exhibit higher sensitivity to environmental stresses, including drought (Finch-Savage and LuebnerMetzger, 2006; Zahra et al., 2021). Studies on Apocynum, rice (Oryza sativa L.), and lentil (Lens culinaris Medikus) have revealed that seed germination and seedling growth are inhibited under drought 
conditions (Biju et al., 2017; Sheteiwy et al., 2018; Yang et al., 2021). The primary reason for this decline in seedling emergence is the reduction in water uptake during the imbibition phase of germination, where all physiological and metabolic processes are inhibited (Fabregas and Fernie, 2019; Patel et al., 2021). In general, carbohydrates and proteins are mobilized to provide substrates and energy for seed germination, where amylases are the key enzymes related to the hydrolysis of starch to soluble sugar, which was reduced by low water availability (Fabregas and Fernie, 2019; Lei et al. 2021; Saharan et al., 2016). The osmotic adjustment in seeds or seedlings during drought, by accumulation of osmolytes, such as sugars, amino acids, and soluble protein, is one of the major adaptive strategies for maintaining osmotic balance, thereby improving water uptake (Ozturk et al., 2021; Sheteiwy et al., 2018; Wu et al., 2019). Moreover, the vital negative effects of drought stress induce excessive generation of reactive oxygen species (ROS), such as singlet oxygen $\left({ }^{1} \mathrm{O}_{2}\right)$, superoxide radicals $\left(\mathrm{O}_{2}{ }^{-{ }^{-}}\right)$, hydroxyl radicals $\left(\mathrm{OH}^{-}\right)$, and hydrogen peroxide $\left(\mathrm{H}_{2} \mathrm{O}_{2}\right)$ (Choudhury et al., 2017; Fang and Xiong, 2015; Razi and Muneer, 2021). Overproduction of ROS under drought stress causes substantial damage to the cellular components, such as cellular membranes, nucleic acid, proteins, and lipids, which may even lead to cell death (Choudhury et al., 2017; Kamal et al., 2021; Sasi et al., 2021). In response to this damage, plants have developed an effective defense mechanism through their antioxidant enzymes, including superoxide dismutase (SOD), catalase (CAT), and polyphenol oxidase (POD), and various non-enzymatic antioxidants like glutathione, ascorbate, and phenolic compounds (Khan et al., 2021; Li et al., 2021; Rai-Kalal et al., 2021).

Although both genetic breeding and gene modification techniques are usually used to overcome abiotic stresses of the seeds, these strategies are commonly limited owing to the high cost, cumbersome process, and particularly restrictions in biosafety regulations. An alternative method for promoting seed germination, crop growth, and plant tolerance against abiotic stresses is seed priming by utilizing various chemicals (Colla et al., 2015; Rai-Kalal et al., 2021; Salah Sheteiwy et al., 2018). This alternative technique has been widely explored by planters because of numerous advantages, including less cumbersome process, low cost, and effectivity, compared to genetic breeding (Marthandan et al., 2020; Zulfiqar, 2021). For example, seed priming with melatonin protect wheat (Triticum aestivum L.) seeds from Cr toxicity by improving its reserve mobilization and antioxidant system (Lei et al., 2021). Priming with salicylic acid substantially increases seed germination of Leymus chinensis under salt-alkali stress (Mabrouk et al., 2019). Protein hydrolysates are a main group of biostimulants, which contain high amounts of polypeptide and free amino acids that are mainly produced by hydrolysis of proteins derived from agroindustrial byproducts from animal or plant sources; hence, their usage is important from environmental and economical points of view (Colla et al., 2015; Calvo et al., 2014). Protein hydrolysates enhance plant performance, especially under various environmental stresses, such as drought, salinity, thermal stress, and nutrient deficiency (Calvo et al., 2014). Plant growth stimulation by seed priming with protein hydrolysates has been observed in Arabidopsis thaliana, maize (Zea mays L.), and tomato (Solanum lycopersicon L.) under abiotic stress (Casadesús et al., 2020; Ertani et al., 2013; Sorrentino et al., 2021). However, to the best of our knowledge, the effect of seed priming with protein hydrolysates on seed germination and seedling growth, as well as the underlying mechanisms under drought stress, remain unclear. 
Tomato (Solanum lycopersicum L.) is an important economic crop, which is usually affected by drought stress and exhibits a reduction in physiological and biochemical processes (Elbadrawy and Sello, 2016). In our study, we evaluated (1) the feasibility of seed priming with pig blood-derived protein hydrolysates (PP) to enhance tomato seed germination and seedling growth; (2) the potential role of PP priming in regulating the reserve mobilization of seeds; and (3) the function of PP priming in preventing osmotic stress and oxidative damage under drought stress. Our results provide a new strategy for the agronomic application of protein hydrolysates in alleviating drought stress in the agriculture.

\section{Materials And Methods}

\section{Plant materials and treatment}

Tomato seeds were purchased from Shouguang City, China. PP was obtained from Win Plus Biotech Co., Ltd (Xiangyang, China), which is a complex mixture of peptides and free amino acids derived from pig blood protein by enzyme hydrolysis. The composition of the peptides and free amino acids is shown in Fig. S1.

Tomato seeds were surface-sterilized with $10 \%$ sodium hypochlorite for $10 \mathrm{~min}$, and then washed three times with distilled water. The seeds were soaked with different concentrations of PP solutions $(0,1,2,3$, and $5 \mathrm{~g} \mathrm{~L}^{-1}$ ) at $20^{\circ} \mathrm{C}$ for $24 \mathrm{~h}$ in the dark. Then, 20 seeds were placed on filter paper moistened with distilled water or $10 \%$ PEG-6000 solution in each $12 \mathrm{~cm}$ diameter Petri dish. Seeds were cultured in an artificial climate chamber with a photoperiod of $16 / 8 \mathrm{~h}$ (day/night), relative humidity of $60 \%$, and temperature of $25 / 16^{\circ} \mathrm{C}$ (day/night). The treatment conditions were as follows: CK (seeds soaked and germinated in distilled water); PEG (seeds soaked in distilled water and germinated in 10\% PEG-6000 solution); PP1 + PEG, PP2 + PEG, PP3 + PEG, and PP5 + PEG (seeds soaked in 1, 2, 3, and $5 \mathrm{~g} \mathrm{~L}^{-1}$ of PP, respectively, and seed germinated in $10 \%$ PEG-6000 solution).

Non-germinated or irregularly germinated seeds were discarded, and then seeds were shelled for physiological and biochemical analysis at $0 \mathrm{~h}, 48 \mathrm{~h}$, and $72 \mathrm{~h}$. Germination rate (\%) was equal to the number of germinated seeds on the 7th day of the germination. Germination potential (\%) was equal to the number of germinated seeds on the 4th day of the germination. The germination index was equal to $\sum(\mathrm{G} i / \mathrm{T} i)$ (where $\mathrm{G} i$ is the germination percentage in times of $\left.\mathrm{T} i\right)$. After 7 days, fresh samples were collected, and fresh weight, root length, and seedling height were determined, and directly stored at $-20^{\circ} \mathrm{C}$ until the completion of biochemical assays.

\section{Analysis of $\alpha$-amylase, $\beta$-amylase, total amylase, and sucrose synthase activities}

Seed samples were collected at $0 \mathrm{~h}, 48 \mathrm{~h}$, and $72 \mathrm{~h}$ after treatment, and the following indices were determined: the $\alpha$-amylase, $\beta$-amylase, and total amylase were measured using 3,5-dinitrosalicylic acid (DNS) method (Biju et al., 2017). For a-amylase determination, tomato seeds $(0.1 \mathrm{~g})$ were homogenized 
with $1.5 \mathrm{~mL}$ of distilled water, and centrifuged at $10000 \times \mathrm{g}$ for at $4^{\circ} \mathrm{C} 10 \mathrm{~min}$. The extract $(0.2 \mathrm{~mL}) \mathrm{was}$ mixed with $0.2 \mathrm{M}$ citrate buffer ( $\mathrm{pH} \mathrm{5.6)}$, and incubated at $70^{\circ} \mathrm{C}$ for $30 \mathrm{~min}$. Then, $2 \mathrm{~mL}$ of DNS and $1 \mathrm{~mL}$ of soluble starch ( $1 \% \mathrm{v} / \mathrm{v})$ were added to a boiling water bath for $5 \mathrm{~min}$, and the absorbance was determined at $540 \mathrm{~nm}$. $\beta$-amylase activity was determined as described above; however, the starch was replaced by amylopectin. The total amylase activity was calculated as the sum of $\alpha$-amylase and $\beta$ amylase activities.

Sucrose synthase activity was determined as described by Verma et al. (2011). Briefly, fresh tomato seeds $(0.1 \mathrm{~g})$ were extracted with $0.1 \mathrm{M}$ Tris-HCl buffer $(\mathrm{pH} 7.6)$ containing $0.3 \mathrm{M}$ mannitol, $0.01 \mathrm{M} \mathrm{MgCl}_{2}$, $0.02 \mathrm{M}$ EDTA, $0.02 \mathrm{M}$ cysteine- $\mathrm{HCl}, 0.02 \mathrm{M}$ diethyldithiocarbamate, and $1.0 \%$ triton $\mathrm{X}-100$ at $4^{\circ} \mathrm{C}$, and incubated at $37^{\circ} \mathrm{C}$ for $30 \mathrm{~min}$. After terminated in a boiling water bath for $10 \mathrm{~min}$, the absorbance of mixture was recorded at $480 \mathrm{~nm}$.

\section{Analysis of starch, soluble Sugar, free amino acid, soluble protein, and proline contents}

Starch, soluble sugar, and free amino acids were extracted using $80 \%$ ethanol (Patel and Parida, 2021). Briefly, fresh tomato seeds or seedlings $(0.2 \mathrm{~g})$ were homogenized in $80 \%(\mathrm{v} / \mathrm{v})$ ethanol, and centrifuged at $10000 \times g$ at $4^{\circ} \mathrm{C}$ for $15 \mathrm{~min}$. The soluble sugar content was determined from the supernatant using the anthrone colorimetric method (Dubois et al., 1951). Free amino acid content was determined by the ninhydrin reagent method (Moore and Stein, 1954). Moreover, starch content was determined by the method of Saharan et al. (2016).

Proline content was measured according to the method of Bates et al. (1973). Briefly, $0.2 \mathrm{~g}$ of samples were added into aqueous sulfosalicylic acid (3\%) and kept in boiling water for $1 \mathrm{~h}$. After the mixture was cooled to room temperature, the ninhydrin and acetic acid was added, and then the mixture was maintained in a boiling water bath for $30 \mathrm{~min}$ and cooled in an ice bath. Subsequently, $5 \mathrm{~mL}$ of toluene was added, and the mixture was placed in the dark for $5 \mathrm{~h}$. Eventually, the absorbance was recorded at $520 \mathrm{~nm}$. The soluble protein content was measured following the Bradford's method (Bradford, 1973).

\section{Assays of ROS, lipid peroxidation, and histochemical detection}

The $\mathrm{H}_{2} \mathrm{O}_{2}$ content in fresh samples were estimated following the method described by Mabrouk et al. (2019). The absorbance of the reaction mixture was recorded at $390 \mathrm{~nm}$, and the content was measured using the calibration curve prepared from $\mathrm{H}_{2} \mathrm{O}_{2}$. The superoxide $\left(\mathrm{O}_{2}{ }^{\cdot-}\right)$ content was estimated using a protocol previously described by Lei et al. (2021), and calculated based on the calibration curve prepared from sodium nitrite. In addition, $\mathrm{H}_{2} \mathrm{O}_{2}$ and $\mathrm{O}_{2}{ }^{-{ }^{-}}$in root tips were visually stained by using $0.1 \% 3,3^{\prime}-$ diaminobenzidine (DAB) and dihydroethidium (NBT), respectively (Sun et al., 2017). After that, the roots were observed and photographed using a stereoscope. 
Membrane lipid peroxidation was determined by measuring the concentration of malondialdehyde (MDA), according to the method of Li et al. (2021). The plasma membrane integrity was detected by staining fresh samples with Evans blue solution $(0.25 \% \mathrm{w} / \mathrm{v})$ by a spectrophotometric assay as described by Sun et al. (2017). After washed extensively, the root samples were observed under a light microscope. Then, the retained Evans blue was released by shaking the samples in $5 \mathrm{~mL}$ of $\mathrm{N}, \mathrm{N}$-dimethylformamide, and the absorbance was read at $600 \mathrm{~nm}$.

\section{Analysis of antioxidant enzymes activities}

Fresh samples $(0.2 \mathrm{~g})$ were homogenized in ice-cold potassium buffer $(50 \mathrm{mM}, \mathrm{pH} 7.8)$ containing $2 \%$ $(\mathrm{w} / \mathrm{v})$ polyvinylpyrrolidone, $1 \mathrm{mM}$ EDTA, and $0.3 \%$ Triton X-100. The homogenate was then centrifuged at $12000 \times g$ at $4^{\circ} \mathrm{C}$ for $20 \mathrm{~min}$, and the supernatant was used for enzyme assays. The activities of superoxide dismutase (SOD, EC 1.15.1.1), peroxidase (POD, EC 1.11.1.7), and catalase (CAT, EC 1.11.1.6) were determined by the methods of Mabrouk et al. (2019).

\section{Analysis of non-enzymatic antioxidant content}

Fresh samples $(0.2 \mathrm{~g})$ were homogenized with $1.5 \mathrm{~mL}$ of $0.5 \mathrm{M}$ EDTA solution containing $3 \%$ trichloroacetic acid, and then centrifuged at $12000 \times \mathrm{g}$ at $4^{\circ} \mathrm{C}$ for $10 \mathrm{~min}$. The supernatant was used to assay the ascorbic acid (AsA) and glutathione (GSH) contents and calculated as described by Zhou et al. (2020).

The analysis of phenolic compounds was conducted using the method described by Zhou, et al. (2018). Briefly, fresh samples were homogenized with $80 \%(\mathrm{v}: \mathrm{v})$ methanol solution and then centrifuged at 10 $000 \times g$ at $4^{\circ} \mathrm{C}$ for $10 \mathrm{~min}$. The supernatant was used to determine the total phenolic, flavonoid, and anthocyanin content.

\section{Analysis of antioxidant activities}

The DPPH free radical scavenging capacity (DFRSC) was measured by recording the decrease of absorbance at $517 \mathrm{~nm}$, and the results were expressed as percent scavenging of DPPH radicals (Zhang et al., 2013). The ferric reducing antioxidant power (FRAP) assay was performed according to Thaipong et al. (2006) using $\mathrm{FeSO}_{4} \cdot 7 \mathrm{H}_{2} \mathrm{O}$ as the calibration, and the results were expressed as FRAP values $\left(\mu \mathrm{M} \mathrm{Fe}{ }^{2+}\right.$ $\mathrm{g}^{-1} \mathrm{FW}$ ).

\section{Statistical analysis}

All data were analyzed using the SPSS statistical software. Data are presented as the mean \pm standard deviation (SD) of at least three independent experiments using one-way analysis of variance (ANOVA). The least significant difference (LSD) test was performed to determine significant differences among the treatments at $P<0.05$.

\section{Results}




\section{Tomato seed germination and seedling growth}

Compared to the control, the PEG treatment negatively affected tomato seed germination, as indicated by the substantial reduction in germination rate, germination potential, and germination index (Fig. 1a-C). However, PP priming positively stimulated seed germination, and the maximum enhancement of germination rate, germination potential, and germination index were observed in the PP2 treatment, which increased by $39.5 \%, 283.5 \%$, and $103.5 \%$, respectively, compared to the PEG treatment. In addition, PP2 treatment significantly alleviated the PEG-induced decrease in seedling growth to the maximum extent, and the seedling fresh weight, seedling height, and root length increased by $33.4 \%, 45.4 \%$, and $22.9 \%$, respectively, compared to the PEG treatment (Fig. 1d-f).

\section{Activity of $\alpha$-amylase, $\beta$-amylase, total amylase, and sucrose synthase}

The activities of $a$-amylase, $\beta$-amylase, and total amylase in tomato seeds gradually increased with germination time (Fig. 2a-c). PP2 priming significantly improved the activities of $\alpha$-amylase, $\beta$-amylase, and total amylase by $14.9 \%, 15.4 \%$, and $15.2 \%$ at $48 \mathrm{~h}$, and by $16.3 \%, 9.35 \%$, and $11.65 \%$ at $72 \mathrm{~h}$, respectively, compared to the PEG treatment. The PEG treatment significantly decreased sucrose synthase activity by $18.6 \%$ at $48 \mathrm{~h}$, compared to the control, whereas PP2 priming reversed the inhibitory effects of PEG on sucrose synthase activity, which was increased by $13.3 \%$ and $9.6 \%$ at $48 \mathrm{~h}$ and $72 \mathrm{~h}$, respectively (Fig. 2d).

\section{Starch, soluble sugar, soluble protein, and free amino acid content in seeds}

A gradual decrease in starch content was observed in the tomato seeds with germination time, and this trend was slowed down by the PEG treatment (Fig. 3a). However, PP2 priming significantly decreased the starch content of seeds by $18.2 \%$ and $10.5 \%$ at $48 \mathrm{~h}$ and $72 \mathrm{~h}$, respectively, compared to the PEG treatment. After germination, the soluble sugar content exhibited an increasing trend at $48 \mathrm{~h}$, followed by a decreasing trend at $72 \mathrm{~h}$ (Fig. $3 \mathrm{~b}$ ). Compared to the PEG treatment, PP2 priming significantly increased the soluble sugar content by $13.5 \%$ and $15.3 \%$ at $48 \mathrm{~h}$ and $72 \mathrm{~h}$, respectively. In addition, the soluble protein and free amino acid content significantly decreased by $28.8 \%$ and $20.3 \%$ at $72 \mathrm{~h}$ in the PEGtreated seeds compared to those in the control (Fig. 3c and d). However, PP2 priming resulted in a considerable improvement in soluble protein and free amino acid content by $30.8 \%$ and $7.3 \%$, respectively, at $72 \mathrm{~h}$ compared to the PEG treatment.

\section{ROS, lipid peroxidation, and membrane integrity}

The levels of $\mathrm{H}_{2} \mathrm{O}_{2}$ and $\mathrm{O}_{2}{ }^{\cdot-}$ in tomato seedlings were determined to investigate the role of PP priming in PEG-induced oxidative damage. The PEG treatment caused higher accumulation of $\mathrm{H}_{2} \mathrm{O}_{2}$ and $\mathrm{O}_{2}{ }^{\cdot-}$ by 
$98.4 \%$ and $142.0 \%$, respectively, compared to the control (Fig. 4a and b). However, PP priming substantially reduced the $\mathrm{H}_{2} \mathrm{O}_{2}$ and $\mathrm{O}_{2}{ }^{\cdot-}$ content of which PP2 treatment resulted in a maximum reduction of $34.9 \%$ and $45.6 \%$, respectively, compared to the PEG treatment. As shown in Fig. $4 \mathrm{e}$ and $\mathrm{f}$, tissue staining for $\mathrm{H}_{2} \mathrm{O}_{2}$ and $\mathrm{O}_{2}{ }^{\cdot-}$ illustrated that the PEG-stressed roots were stained extensively, while roots primed by PP along with PEG showed slight staining. Moreover, tomato seedlings treated with PEG exhibited higher levels of MDA and Evans blue uptake compared to the control (Fig. 4c and d). However, PP priming substantially decreased the MDA content and Evans blue uptake, with maximal reductions of $18.5 \%$ and $47.2 \%$, respectively, observed in the PP2 treatment. This result was further verified by the root histochemical staining with Evans blue (Fig. 4g).

The activities of SOD, POD, and CAT were increased by the PEG treatment in tomato seedlings compared to the control (Fig. 5a). The PP2 and PP3 priming further significantly increased the activities of SOD (by $40.4 \%$ and $23.7 \%$, respectively), POD (by $85.9 \%$ and $41.2 \%$, respectively), and CAT (by $82.5 \%$ and $49.7 \%$, respectively), whereas PP1 priming only enhanced the activities of POD and CAT by $18.3 \%$ and $27.9 \%$, respectively, compared to the PEG treatment. Moreover, higher contents of non-enzymatic antioxidants, including total phenolics, flavonoids, anthocyanins, ASA, and GSH, were also observed in the PEG-treated seedlings (Fig. 5b). PP priming further improved the total phenolics, flavonoids, anthocyanins, ASA, and GSH contents, and their maximum enhancement was observed in PP2 treatment by $53.1 \%, 57.1 \%$, $325.7 \%, 64.6 \%$, and $33.6 \%$, respectively, compared to the PEG treatment. As a result, compared to the PEG treatment, the highest increase in DFRSC and FRAP were found in the PP2 treatment by $28.8 \%$ and $58.0 \%$, respectively (Fig. 6).

\section{Soluble sugar, soluble protein, and proline in tomato seedlings}

Soluble sugar, soluble protein, and proline are important substances involved in the osmotic adjustment of plants under drought stress. Compared to the control, the PEG treatment increased the levels of soluble sugar and proline significantly by $14.7 \%$ and $27.0 \%$, respectively, and decreased the content of soluble protein by $23.5 \%$ (Fig. 7). However, PP priming positively stimulated the accumulation of these osmolytes, and the maximum enhancement of soluble sugar, soluble protein, and proline were observed in the PP2 treatment, which increased by $170.4 \%, 15.9 \%$, and $82.3 \%$, respectively, compared to the PEG treatment.

\section{Discussion}

Drought is a main abiotic stress that threatens plant growth, development, and yield production by inhibiting various physiological processes (Fabregas and Fernie, 2019; Razi and Muneer, 2021; Trenberth et al., 2013). Seed germination and seedling growth, as the critical stages of plant growth, are susceptible to drought stress, usually exhibiting low germination rates, inhibition of root elongation, and biomass reduction (Marthandan et al., 2020; Finch-Savage and Leubner-Metzger, 2006). In the present study, drought stress induced by the usage of $10 \%$ PEG significantly reduced the germination rate, germination 
potential, and germination index of tomato seeds, as well as the seedling fresh weight, seedling height, and root length (Fig. 1). In order to reduce the negative effects of drought stress on seed germination and seedling growth, a low-cost and feasible method known as seed priming has been widely used to improve drought stress tolerance (Marthandan et al., 2020; Salah Sheteiwy et al., 2018; Zulfiqar, 2021).

Remarkably, seed priming with PP significantly alleviated drought-induced inhibition of seed germination and seedling growth. Notably, this positive effect of PP application is perhaps due to the high supply of active peptides and amino acids, which confer crop tolerance to various abiotic stresses by regulating biochemical and physiological processes (Colla et al., 2015). Therefore, to the best of our knowledge, our study is the first to verify that PP could alleviate the reduced tomato seed germination and seedling growth; thus, it could be a potential strategy to improve seed tolerance to drought stress.

Seed germination is a complex physical and chemical process, beginning with water uptake of dry seeds to radicle protrusion and growth, where the necessary energy is supplied by the degradation of storage substances, such as starch and protein (Lei et al., 2021; Finch-Savage and Leubner-Metzger, 2006). It has been widely indicated that seed reserve content is positively correlated with the germination rate and seedling growth of wheat (Triticum aestivum L.), rice (Oryza sativa L.), and lentil (Lens culinaris Medikus) (Biju et al., 2017; Cheng et al., 2015; Lei et al., 2021). However, mobilization of starch and protein is prevented under abiotic stresses, including drought (Fabregas and Fernie, 2019; Marthandan et al., 2020). The present study showed that drought stress remarkedly inhibited the activities of a-amylase, $\beta$-amylase, total amylase, and sucrose synthase, leading to a reduction in the hydrolysis of starch to soluble sugars (Fig. 2 and Fig. 3). In addition, the PEG-induced water deficiency also adversely decreased the content of soluble protein and free amino acids, suggesting that drought stress inhibited the metabolism of sugar and degradation of storage proteins during germination. However, PP priming significantly increased the activities of amylase and sucrose synthase and the levels of soluble sugar, soluble protein, and free amino acids in tomato seeds. These results indicate that PP may enhance amylase activity and subsequent reserve mobilization to stimulate seed germination under drought stress. Previous findings have revealed that protein hydrolysates are closely associated with the levels of endogenous hormones, as their biosynthesis, stimulating the activity of various enzymes, including amylase (Casadesús et al., 2020; Sorrentino et al., 2021).

Plants usually accumulate a variety of substances for osmotic regulation, such as proline, betaine, soluble protein, and soluble sugar, which help to maintain turgor pressure, promote water absorption and retention, and improve tolerance among plants against drought stress (Ozturk et al., 2021; Razi and Muneer, 2021). In the present study, rapid increases in soluble sugars, soluble protein, and proline accumulation in tomato seedlings were also observed under drought conditions. Seed priming with PP resulted in further improvements in soluble sugars, soluble protein, and proline accumulation (Fig. 3 and Fig. 7), which may be beneficial for the osmotic homeostasis under drought stress. Similar to our results, exogenous application of silicon, quercetin, and melatonin partially improved drought resistance via increasing the levels of soluble sugars, soluble protein, and proline in plants (Lei et al., 2021; Patel et al., 2021; Yang et al., 2021). Proline, an amino acid act as an essential osmolyte, and its accumulation in drought-treated seedlings after PP priming might be due to the high proline supply of PP, which contained 
$2.45 \%$ of proline (Fig. S1). Therefore, it can be speculated that PP priming might play a key role in seed tolerance to drought stress by improving the accumulation of active osmolytes, thereby reducing osmotic toxicity.

Under normal growth conditions, the production and removal of ROS are in a dynamic balance, which does not cause damage to plants in general (Choudhury et al., 2017). However, plant standard homeostasis is remarkably perturbed because of the drought-caused excessive generation of ROS, such as $\mathrm{O}_{2}{ }^{--},{ }^{1} \mathrm{O}_{2}$, and $\mathrm{H}_{2} \mathrm{O}_{2}$ (Marthandan et al., 2020). The results of this study showed that the contents of $\mathrm{O}_{2}{ }^{--}$and $\mathrm{H}_{2} \mathrm{O}_{2}$ significantly increased under drought stress, causing an excessive production of ROS (Fig. 4a and b). Overproduction of ROS under abiotic stress usually leads to an oxidative damage to the cellular components, leading to membrane lipid peroxidation and cell membrane destruction (Kamal et al., 2021; Sasi et al., 2021; Sun et al., 2017). The MDA and Evans blue uptake are considered as key indicators of lipid peroxidation and integrity of the plasma membrane in plants to reflect the degree of membrane damage (Sun et al., 2017). Under drought stress, the augmented MDA and Evans blue uptake were observed compared to the control (Fig. $4 \mathrm{c}$ and d). However, PP priming significantly reduced the contents of $\mathrm{O}_{2}{ }^{\cdot-}$ and $\mathrm{H}_{2} \mathrm{O}_{2}$ in seedlings, thereby obviously minimizing the oxidative damage, as indicated by the reduced MDA and Evans blue uptake under drought stress (Fig. 4a-d). Moreover, histochemical staining also clearly demonstrated that drought stress could cause rapid accumulation of $\mathrm{O}_{2}{ }^{-{ }^{-}}$and $\mathrm{H}_{2} \mathrm{O}_{2}$, resulting in a subsequent oxidative damage to the cell membrane in the root tips; however, PP priming could effectively reduce the widespread staining of root tips (Fig. 4e-g). Altogether, these data indicate that seed priming with PP enables tomato seedlings to maintain ROS at an appropriate level, thereby contributing to enhanced drought tolerance.

To overcome oxidative damage, plants invoke efficient antioxidant defense mechanisms including enzymatic and non-enzymatic antioxidants (Fang and Xiong, 2015; Khan et al., 2021). As the first line of defense mechanisms, SOD is an important enzyme in catalyzing the disproportionation of $\mathrm{O}_{2}{ }^{\cdot-}$ to $\mathrm{H}_{2} \mathrm{O}_{2}$. Furthermore, the $\mathrm{H}_{2} \mathrm{O}_{2}$ produced in response to superoxide dismutase or other metabolic activities can be reduced to $\mathrm{H}_{2} \mathrm{O}$ by the action of CAT and POD, thereby decreasing ROS toxicity (Fang and Xiong, 2015; Patel and Paroda, 2021). It was noticed that the activities of SOD, POD, and CAT in tomato seedlings were largely upregulated after the PP priming, compared to the PEG treatment alone (Fig. 5a). The results in this study are in accordance with Sitohy et al. (2020), who indicated that pumpkin seed protein hydrolysate treatment could enhance CAT and SOD activities, which is positively related to salt tolerance. Moreover, other ROS scavenging antioxidants are a class of low molecular weight compounds such as phenolic compounds, carotenoids, GSH, and AsA, which can effectively scavenge the accumulation of ROS in plants, and thus protect them from oxidative damage under abiotic stresses (Li et al., 2021; Zhou, et al., 2018). In our study, drought stress substantially increased the contents of total phenolics, flavonoids, anthocyanins, AsA, and GSH in tomato seedlings, whereas PP priming further improved these antioxidant contents (Fig. 5b). Consequently, this results in a considerable increase in antioxidant activities as indicated by DFRSC and FRAP in tomato seedlings (Fig. 6). In addition, a large number of antioxidant peptides have been identified from different sources of protein hydrolysates that exhibit 
strong antioxidant capacity (Bougatef et al., 2010; Wen et al., 2020). Therefore, the decreased ROS accumulation in tomato seedlings after PP priming might be partially due to the presence of some antioxidant peptides in PP. Subsequently, these results indicate that seed priming with PP effectively scavenge ROS through improving the activities of antioxidant enzymes and accumulation of antioxidant compounds, and consequently enhancing the tomato seed tolerance to drought stress.

\section{Conclusions}

In conclusion, exogenous PP could be a feasible priming agent for promoting seed germination and seedling growth of tomato plants under drought conditions (Fig. 8). First, PP priming may improve reserve mobilization by increasing amylase activity and soluble sugar, soluble protein, and free amino acid content; second, PP priming may reduce osmotic toxicity by enhancing the accumulation of osmolytes; and third, PP priming may decrease ROS generation via increasing antioxidant systems, thereby minimizing the oxidative damage under drought stress. Thus, our findings provide a new and effective method for reducing drought stress and promoting plant growth.

\section{Declarations}

The authors declare no competing financial interest.

\section{Acknowledgements}

This researched was funded by the Shandong Provincial Natural Science Foundation (ZR2020QC161), and the Research Fund for Introduced High-Level Talents of Qingdao Agricultural University (663/1120106). The authors thank Mr. Fengliang Sun of the Win Plus Biotech Co., Ltd (Xiangyang, China) for assistance in providing the PP product.

\section{Authors' contributions}

Conceptualization: Junliang Li and Weiwei Zhou. Methodology: Weiwei Zhou and Weixuan Wang. Data curation: Weixuan Wang and Chenglong Zhang. Writing-original draft preparation: Weiwei Zhou and Weixuan Wang. Writing-review and editing: Haofeng Lv, Junliang Li, and Bin Liang. Visualization: Weiwei Zhou, Weixuan Wang, and Wenlong Zheng. Funding acquisition: Weiwei Zhou.

\section{Corresponding author}

*Weiwei Zhou, College of Resource and Environment, Qingdao Agricultural University, Qingdao 266000, China. E-mail address: qnzhouww@qau.edu.cn

*Junliang Li, College of Resource and Environment, Qingdao Agricultural University, Qingdao 266000, China. E-mail address: jlli1962@163.com.

\section{References}


1. Anderson R, Bayer PE, Edwards D (2020) Climate change and the need for agricultural adaptation. Curr. Opin. Plant Biol 56: 197-202.

2. Bailey-Serres J, Lee SC, Brinton E (2012) Waterproofing crops: effective flooding survival strategies. Plant Physiol 160: 1698-1709.

3. Bai Y, Deng X, Zhang Y, Wang C, Liu Y (2019) Does climate adaptation of vulnerable households to extreme events benefit livestock production? J Clean Prod 210: 358-365.

4. Bates LS, Waldren RP, Teare I (1973) Rapid determination of free proline for water-stress studies. Plant Soil 39: 205-207.

5. Biju S, Fuentes S, Gupta D (2017) Silicon improves seed germination and alleviates drought stress in lentil crops by regulating osmolytes, hydrolytic enzymes and antioxidant defense system. Plant Physiol Biochem 119: 250-264.

6. Bougatef A, Nedjar-Arroume N, Manni L, Ravallec R, Barkia A, Guillochon D, Nasri M (2010) Purification and identification of novel antioxidant peptides from enzymatic hydrolysates of sardinelle (Sardinella aurita) by-products proteins. Food Chem 118: 559-565.

7. Bradford MM (1976) A rapid and sensitive method for the quantitation of microgram quantities of protein utilizing the principle of protein dye binding. Anal Biochem 72: 248-254.

8. Calvo P, Nelson L, Kloepper JW (2014) Agricultural uses of plant biostimulants. Plant Soil 383: 3-41.

9. Casadesús A, Pérez-Llorca M, Munné-Bosch S, Polo J (2020) An enzymatically hydrolyzed animal protein-based biostimulant (Pepton) increases salicylic acid and promotes growth of tomato roots under temperature and nutrient stress. Front Plant Sci 11: 953.

10. Cheng J, Cheng X, Wang L, He Y, An C, Wang Z, Zhang H (2015) Physiological characteristics of seed reserve utilization during the early seedling growth in rice. Braz $\mathrm{J}$ Bot 38: 751-759.

11. Choudhury FK, Rivero RM, Blumwald E, Mittler R (2017) Reactive oxygen species, abiotic stress and stress combination. Plant J 90: 856-867.

12. Colla G, Nardi S, Cardarelli M, Ertani A, Lucini L, Canaguier R, Rouphael Y (2015) Protein hydrolysates as biostimulants in horticulture. Sci Hortic 196: 28-38.

13. Dubois M, Gilles K, Hamilton J, Rebers P, Smith F (1951) A colorimetric method for the determination of sugars. Nature 168: 167-167.

14. Elbadrawy E, Sello A (2016) Evaluation of nutritional value and antioxidant activity of tomato peel extracts. Arab J Chem 9: S1010-S1018.

15. Ertani A, Schiavon M, Muscolo A, Nardi S (2013) Alfalfa plant-derived biostimulant stimulate shortterm growth of salt stressed Zea mays L. plants. Plant Soil 364: 145-158.

16. Fabregas N, Fernie AR (2019) The metabolic response to drought. J Exp Bot 70: 1077-1085.

17. Fang $Y$, Xiong $L$ (2015) General mechanisms of drought response and their application in drought resistance improvement in plants. Cell Mol Life Sci 72: 673-89.

18. Finch-Savage WE, Leubner-Metzger G (2006) Seed dormancy and the control of germination. New Phytol 171: $501-23$. 
19. Kamal KY, Khodaeiaminjan M, Yahya G, El-Tantawy AA, Abdel El-Moneim D, El-Esawi MA, Abd-Elaziz MAA, Nassrallah AA (2021) Modulation of cell cycle progression and chromatin dynamic as tolerance mechanisms to salinity and drought stress in maize. Physiol Plant 172, 684-695.

20. Khan I, Awan SA, Ikram R, Rizwan M, Akhtar N, Yasmin H, Sayyed RZ, Ali S, Ilyas N (2021) Effects of 24-epibrassinolide on plant growth, antioxidants defense system, and endogenous hormones in two wheat varieties under drought stress. Physiol Plant 172: 696-706.

21. Lei K, Sun S, Zhong K, Li S, Hu H, Sun C, Zheng Q, Tian Z, Dai T, Sun J (2021) Seed soaking with melatonin promotes seed germination under chromium stress via enhancing reserve mobilization and antioxidant metabolism in wheat. Ecotoxicol Environ Saf 220: 112241.

22. Li B, Fan R, Sun G, Sun T, Fan Y, Bai S, Guo S, Huang S, Liu J, Zhang H, Wang P, Zhu X, Song C-p (2021) Flavonoids improve drought tolerance of maize seedlings by regulating the homeostasis of reactive oxygen species. Plant Soil 461: 389-405.

23. Mabrouk B, Kâab SB, Rezgui M, Majdoub N, Teixeira da Silva JA, Kâab, LBB (2019) Salicylic acid alleviates arsenic and zinc toxicity in the process of reserve mobilization in germinating fenugreek (Trigonella foenum-graecum L.) seeds. S Afr J Bot 124: 235-243.

24. Marthandan V, Geetha R, Kumutha K, Renganathan VG, Karthikeyan A, Ramalingam J (2020) Seed priming: A feasible strategy to enhance drought tolerance in crop plants. Int J Mol Sci 21: 8258.

25. Moore S, Stein WH (1954) A modified ninhydrin reagent for the photometric determination of amino acids and related compounds. J Biol Chem 211: 907-913.

26. Ozturk M, Turkyilmaz Unal B, Garcia-Caparros P, Khursheed A, Gul A, Hasanuzzaman M (2021) Osmoregulation and its actions during the drought stress in plants. Physiol Plant 172: 1321-1335.

27. Patel M, Fatnani D, Parida AK (2021) Silicon-induced mitigation of drought stress in peanut genotypes (Arachis hypogaea L.) through ion homeostasis, modulations of antioxidative defense system, and metabolic regulations. Plant Physiol Biochem 166: 290-313.

28. Patel M, Parida AK (2021) Salinity alleviates the arsenic toxicity in the facultative halophyte Salvadora persica L. by the modulations of physiological, biochemical, and ROS scavenging attributes. J Hazard Mater 401: 123368.

29. Rai-Kalal $\mathrm{P}$, Tomar RS, Jajoo A (2021) $\mathrm{H}_{2} \mathrm{O}_{2}$ signaling regulates seed germination in $\mathrm{ZnO}$ nanoprimed wheat (Triticum aestivum L.) seeds for improving plant performance under drought stress. Environ Exp Bot 189: 104561.

30. Razi K, Muneer S (2021) Drought stress-induced physiological mechanisms, signaling pathways and molecular response of chloroplasts in common vegetable crops. Crit Rev Biotechnol 41: 669-691.

31. Saharan V, Kumaraswamy RV, Choudhary RC, Kumari S, Pal A, Raliya R, Biswas P (2016) Cu-chitosan nanoparticle mediated sustainable approach to enhance seedling growth in maize by mobilizing reserved food. J Agric Food Chem 64: 6148-6155.

32. Sasi M, Awana M, Samota MK, Tyagi A, Kumar S, Sathee L, Krishnan V, Praveen S, Singh A (2021) Plant growth regulator induced mitigation of oxidative burst helps in the management of drought stress in rice (Oryza sativa L.). Environ Exp Bot 185, 104413. 
33. Sheteiwy MS, Gong D, Gao Y, Pan R, Hu J, Guan Y (2018) Priming with methyl jasmonate alleviates polyethylene glycol-induced osmotic stress in rice seeds by regulating the seed metabolic profile. Environ Exp Bot 153: 236-248.

34. Sitohy MZ, Desoky E-SM, Osman A, Rady MM (2020) Pumpkin seed protein hydrolysate treatment alleviates salt stress effects on Phaseolus vulgaris by elevating antioxidant capacity and recovering ion homeostasis. Sci Hortic 271: 109495.

35. Sorrentino M, De Diego N, Ugena L, Spichal L, Lucini L, Miras-Moreno B, Zhang L, Rouphael Y, Colla G, Panzarova K (2021) Seed priming with protein hydrolysates improves Arabidopsis growth and stress tolerance to abiotic stresses. Front Plant Sci 12: 626301.

36. Sun C, Liu L, Zhou W, Lu L, Jin C, Lin X (2017) Aluminum induces distinct changes in the metabolism of reactive oxygen and nitrogen species in the roots of two wheat genotypes with different aluminum resistance. J Agric Food Chem 65: 9419-9427.

37. Thaipong K, Boonprakob U, Crosby K, Cisneros-Zevallos L, Hawkins Byrne D (2006) Comparison of ABTS, DPPH, FRAP, and ORAC assays for estimating antioxidant activity from guava fruit extracts. $J$ Food Compos Anal 19: 669-675.

38. Trenberth KE, Dai A, van der Schrier G, Jones PD, Barichivich J, Briffa KR, Sheffield J (2013) Global warming and changes in drought. Nat Clim Change 4:17-22.

39. Trevisan S, Manoli A, Quaggiotti S (2019) A novel biostimulant, belonging to protein hydrolysates, mitigates abiotic stress effects on maize seedlings grown in hydroponics. Agronomy 9: 28.

40. Verma AK, Upadhyay SK, Verma PC, Solomon S, Singh SB (2011) Functional analysis of sucrose phosphate synthase (SPS) and sucrose synthase (SS) in sugarcane (Saccharum) cultivars. Plant Biol 13: $325-32$.

41. Wen C, Zhang J, Feng Y, Duan Y, Ma H, Zhang H (2020) Purification and identification of novel antioxidant peptides from watermelon seed protein hydrolysates and their cytoprotective effects on $\mathrm{H}_{2} \mathrm{O}_{2}$-induced oxidative stress. Food Chem 327: 127059.

42. Wu Q, Wang M, Shen J, Chen D, Zheng Y, Zhang W (2019) ZmOST1 mediates abscisic acid regulation of guard cell ion channels and drought stress responses. J Integr Plant Biol 61: 478-491.

43. Yang J, Zhang L, Jiang L, Zhan YG, Fan GZ (2021) Quercetin alleviates seed germination and growth inhibition in Apocynum venetum and Apocynum pictum under mannitol-induced osmotic stress. Plant Physiol Biochem 159: 268-276.

44. Zahra N, Wahid A, Hafeez MB, Ullah A, Siddique KHM, Farooq M (2021) Grain development in wheat under combined heat and drought stress: Plant responses and management. Environ Exp Bot 188: 104517.

45. Zhang R, Zeng Q, Deng Y, Zhang M, Wei Z, Zhang Y, Tang X (2013) Phenolic profiles and antioxidant activity of litchi pulp of different cultivars cultivated in Southern China. Food Chem 136: 1169-1176.

46. Zhou W, Chen Y, Xu H, Liang X, Hu Y, Jin C, Lu L, Lin X (2018) Short-term nitrate limitation prior to harvest improves phenolic compound accumulation in hydroponic-cultivated lettuce (Lactuca sativa L.) without reducing shoot fresh weight. J Agric Food Chem 66: 10353-10361. 
47. Zhou W, Lv T, Hu Y, Liu W, Bi Q, Jin C, Lu L, Lin X (2020) Effect of nitrogen limitation on antioxidant qualities is highly associated with genotypes of lettuce (Lactuca sativa L.). Pedosphere 30: 414425.

48. Zulfiqar F (2021) Effect of seed priming on horticultural crops., Sci Hortic 286: 110197.

Figures

(a)

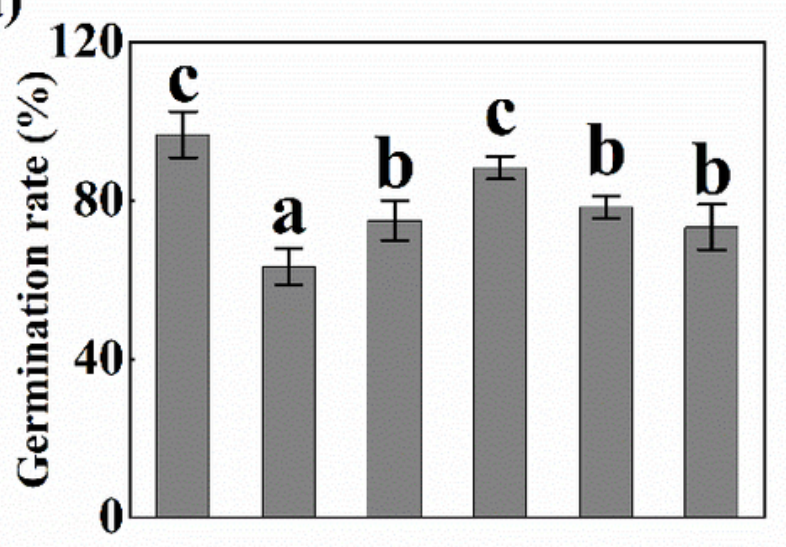

(c)

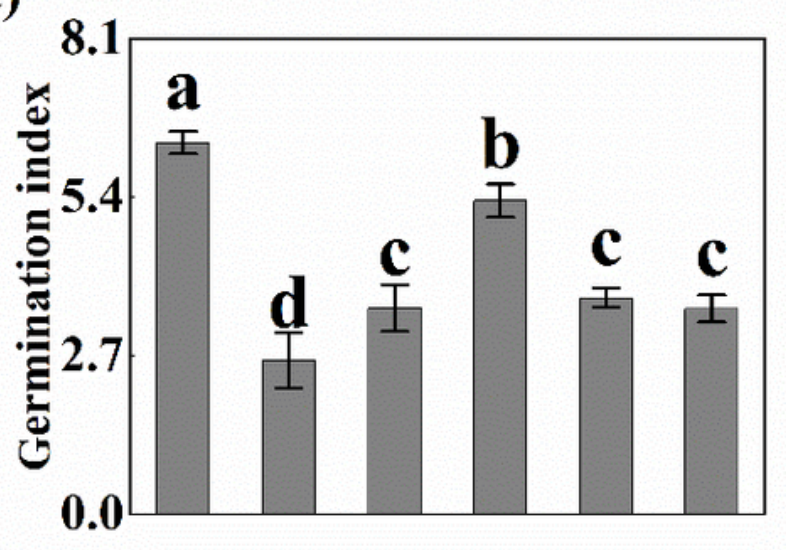

(e)

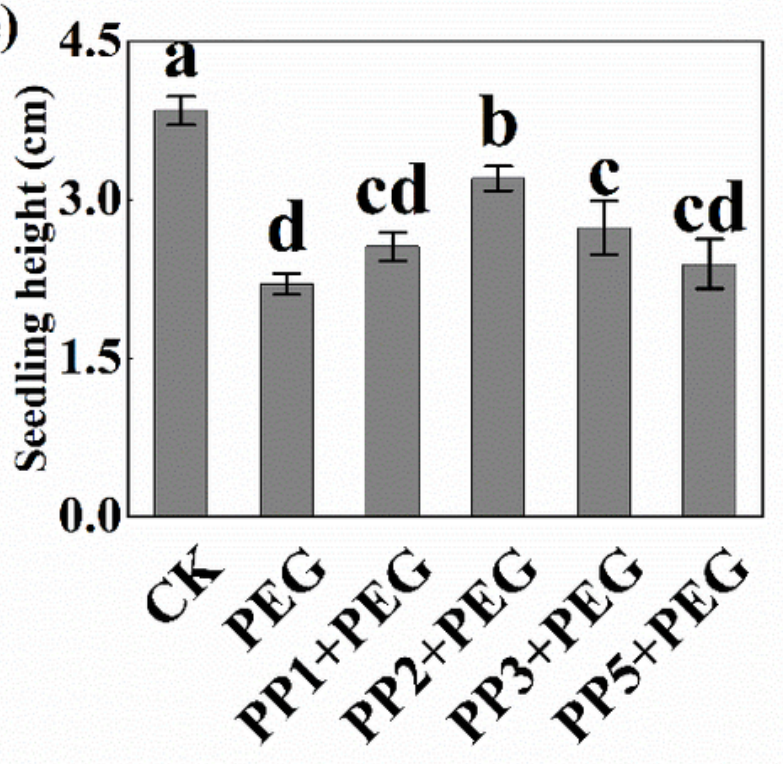

(b)

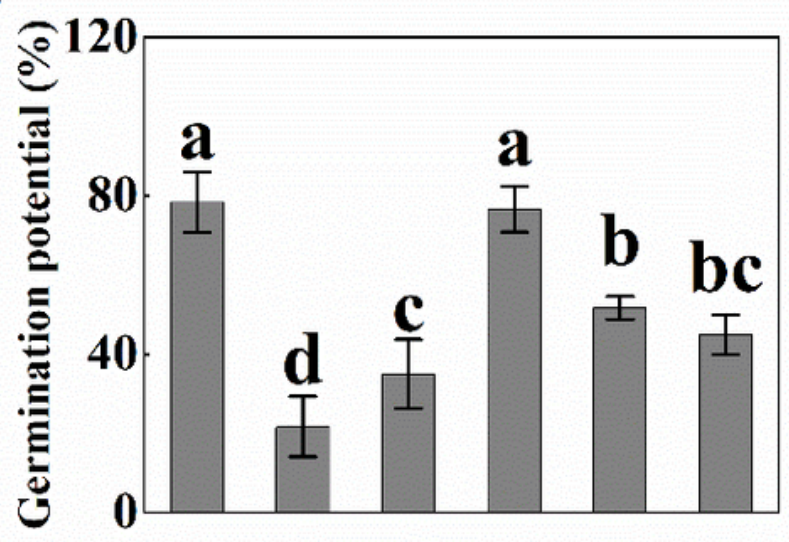

(d)

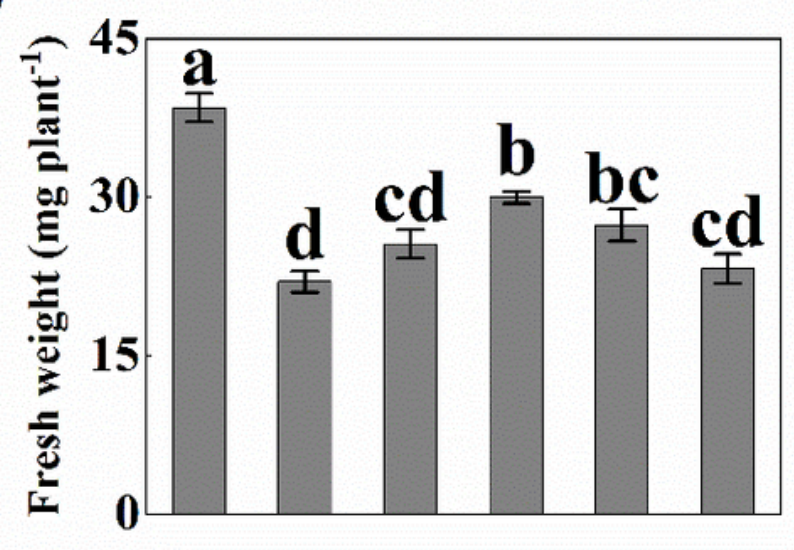

(f)

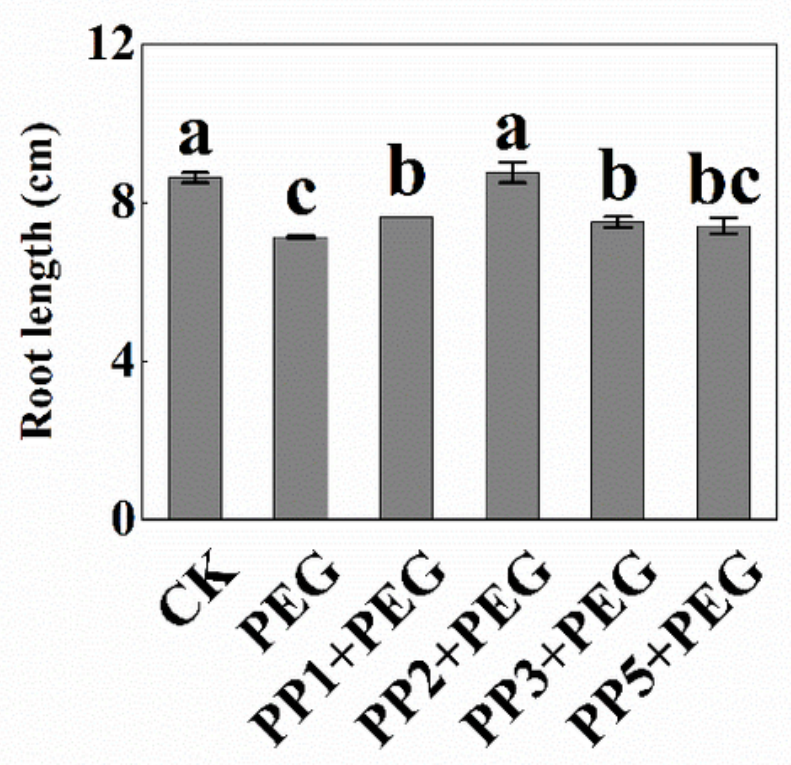


Figure 1

Effects of PP priming on the seed germination rate (a), generation potential (b), generation index (c), seedling fresh weight (d), seedling height (e), and root length $(f)$ of tomato under drought stress. Different letters indicate a significant difference at $\mathrm{P}<0.05$.

(a)

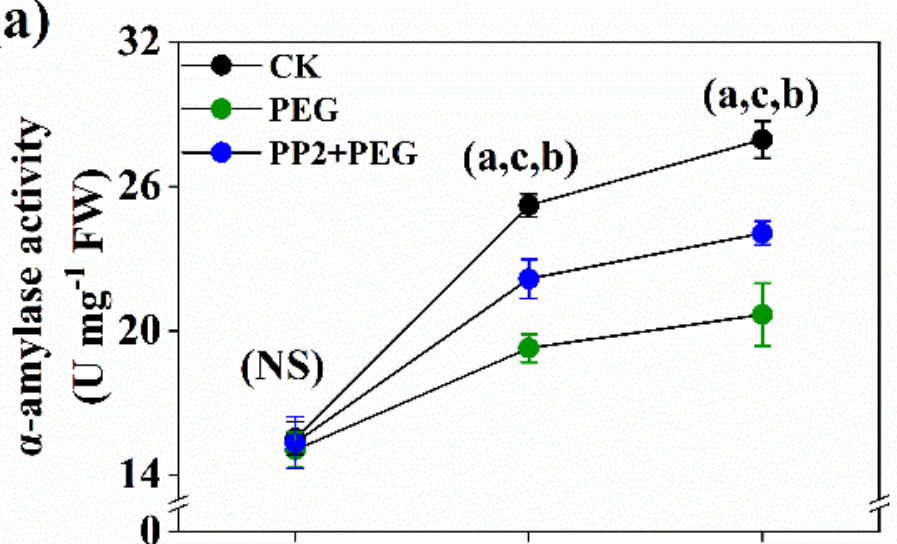

(c)

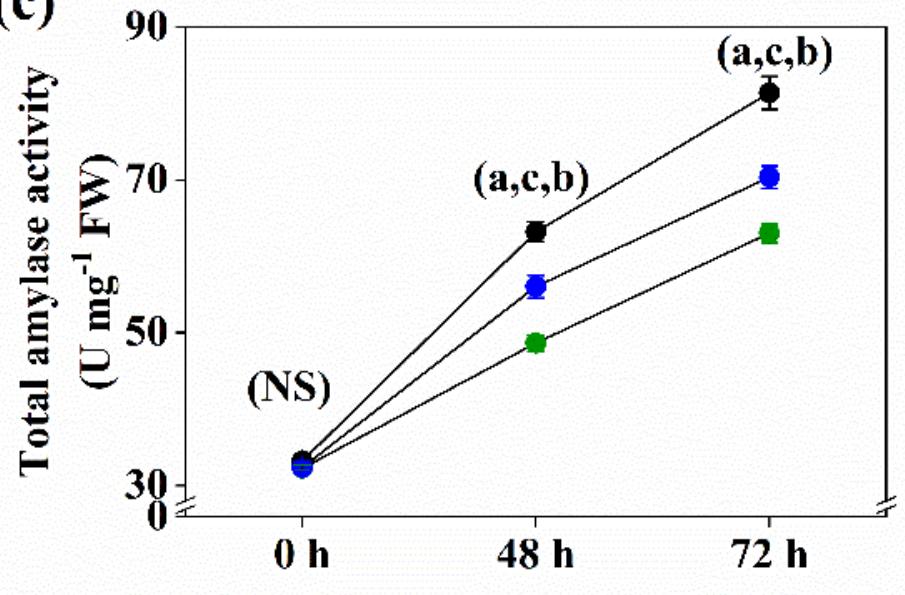

(b)

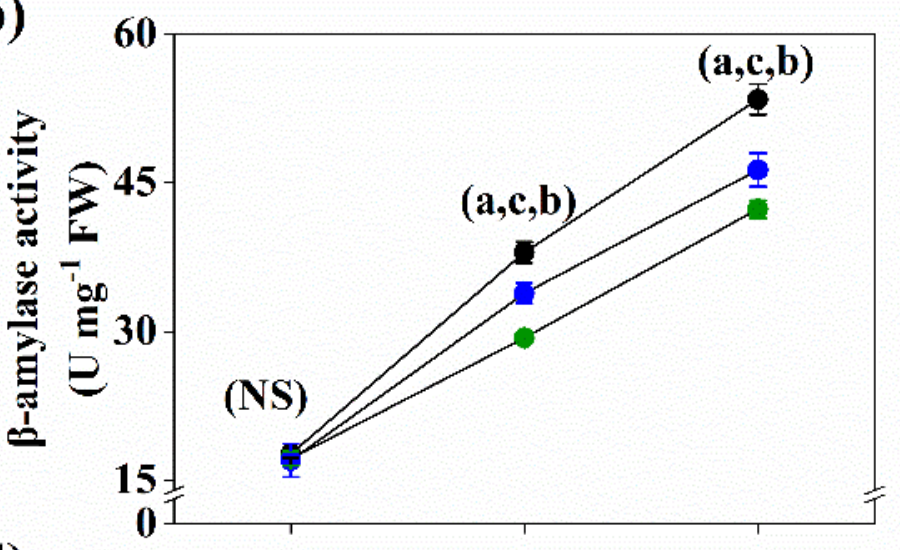

(d)

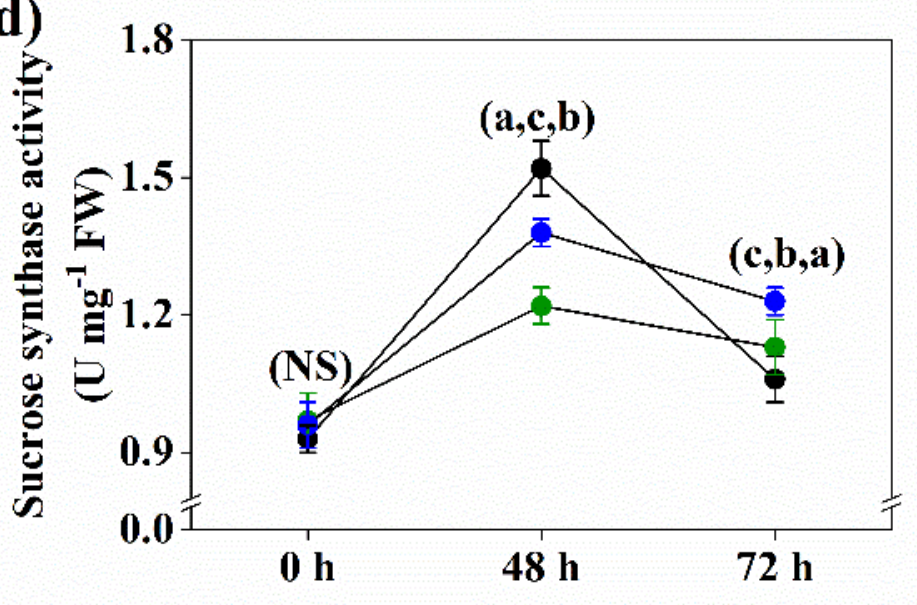

Figure 2

Effects of PP priming on a-amylase (a), $\beta$-amylase (b), total amylase (c), and sucrose synthase activity (d) of tomato seeds under drought stress after germination. Different letters indicate a significant difference at $\mathrm{P}<0.05$. 
(a)

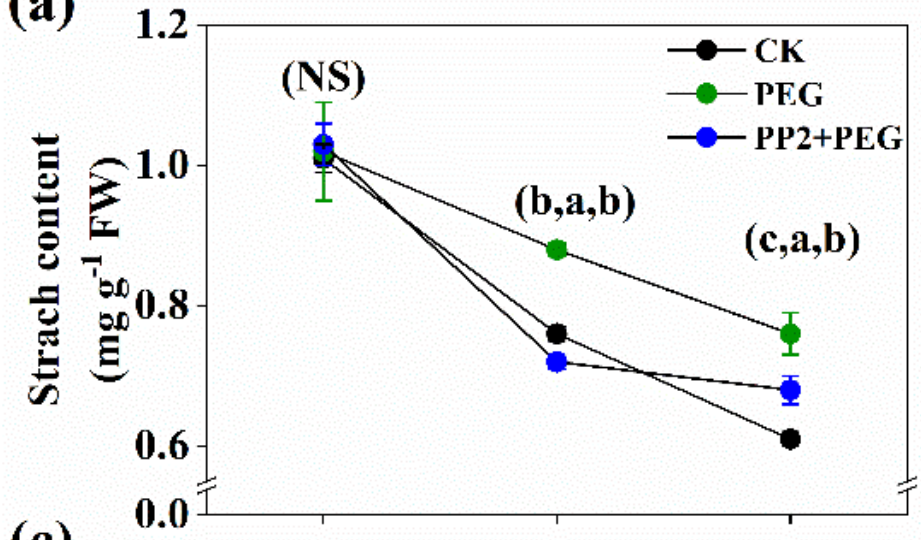

(c)

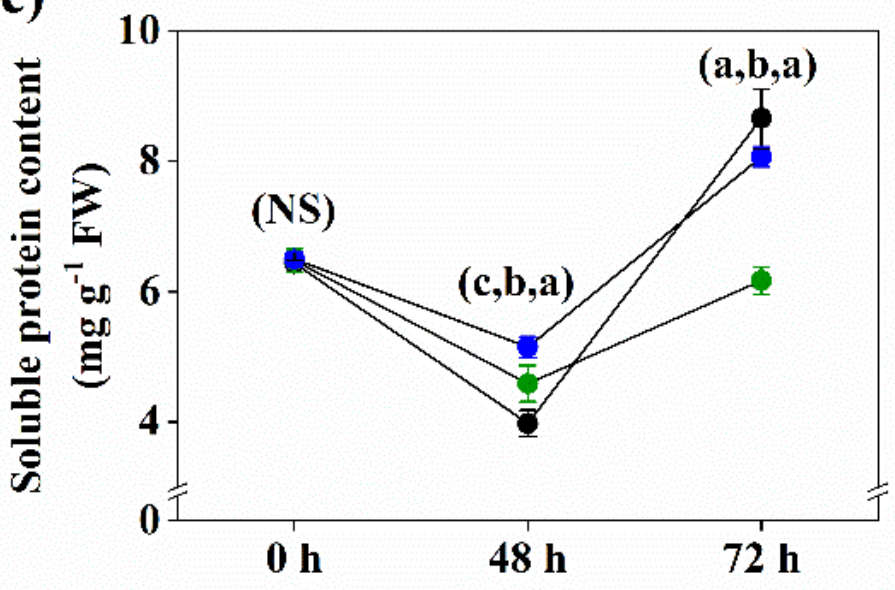

(b)

(d)
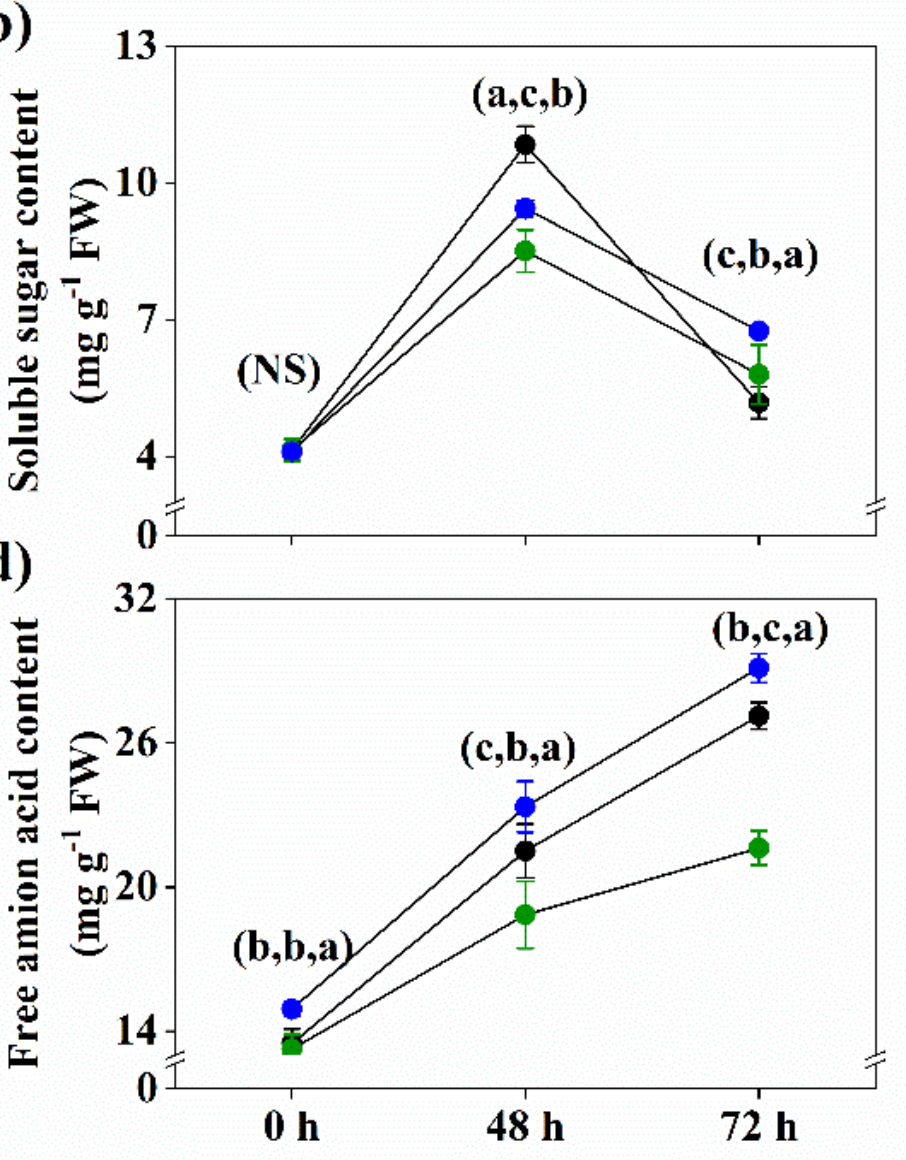

Figure 3

Effects of PP priming on starch (a), soluble sugar (b), soluble protein (c), and free amino acid content (d) of tomato seeds under drought stress after germination. Different letters indicate a significant difference at $\mathrm{P}<0.05$. 
(a)

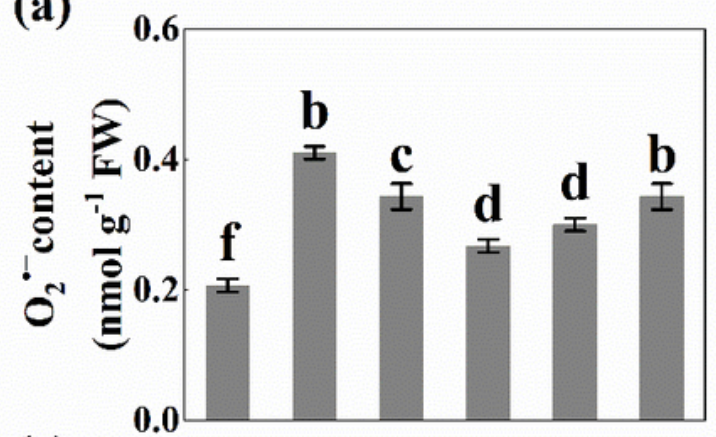

(c)

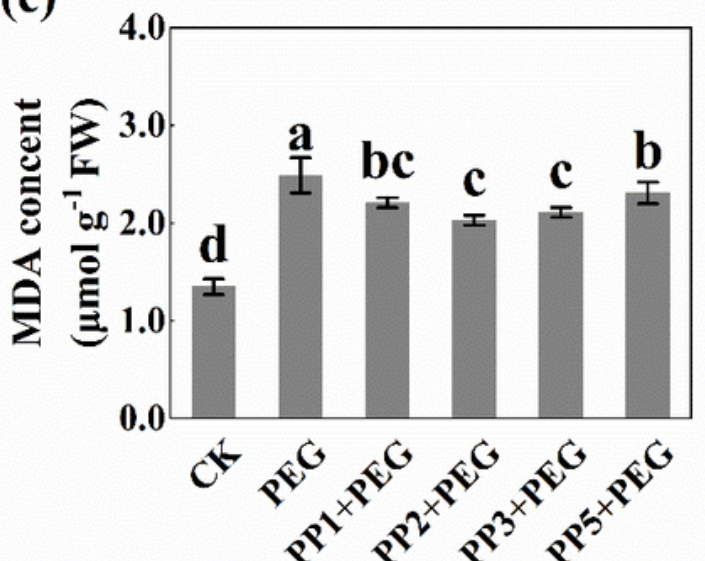

(b)

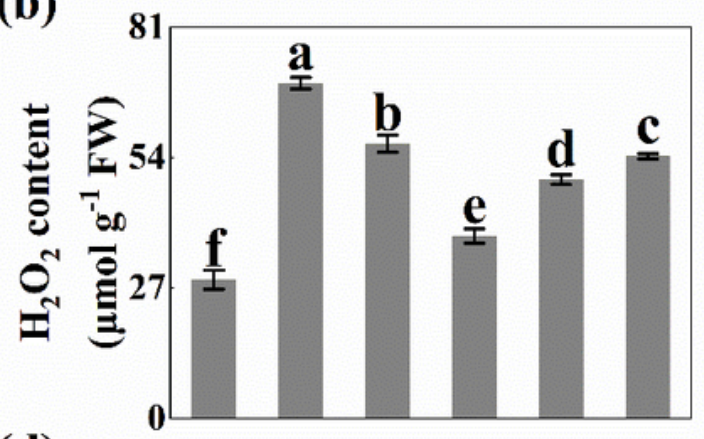

(d)

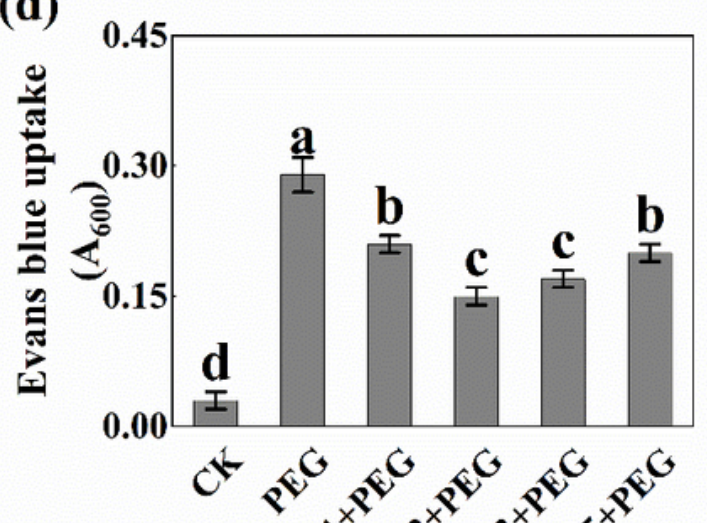

(e)

(f)
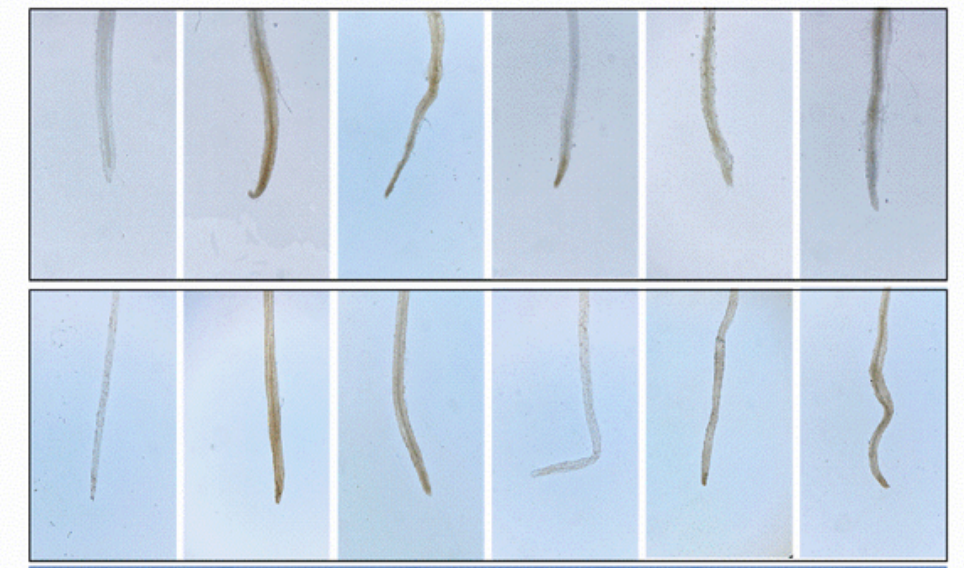

(g)

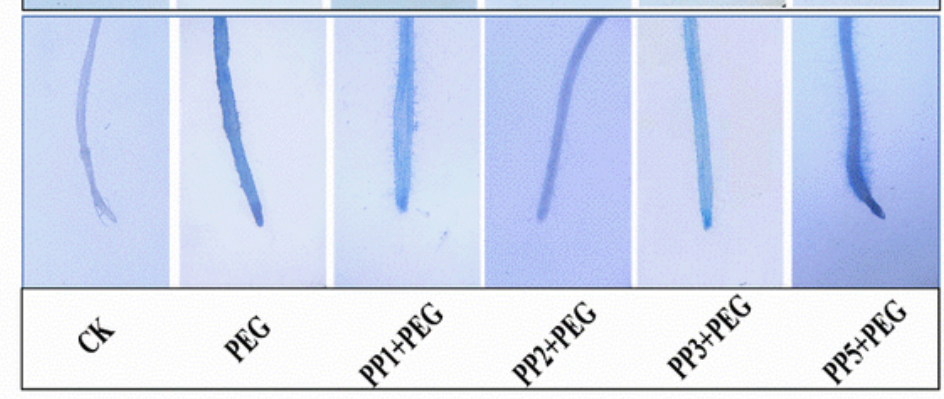

\section{Figure 4}

Effects of PP priming on the level of 02•- (a), H2O2 (b), MDA (c), and Evans blue uptake (d) of tomato seedling under drought stress. Histochemical visualization of $02 \cdot-(e), \mathrm{H} 2 \mathrm{O} 2$ (f), and membrane integrity (g) was performed with DAB, NBT, and Evans blue staining respectively. Different letters indicate a significant difference at $\mathrm{P}<0.05$. 
(a)
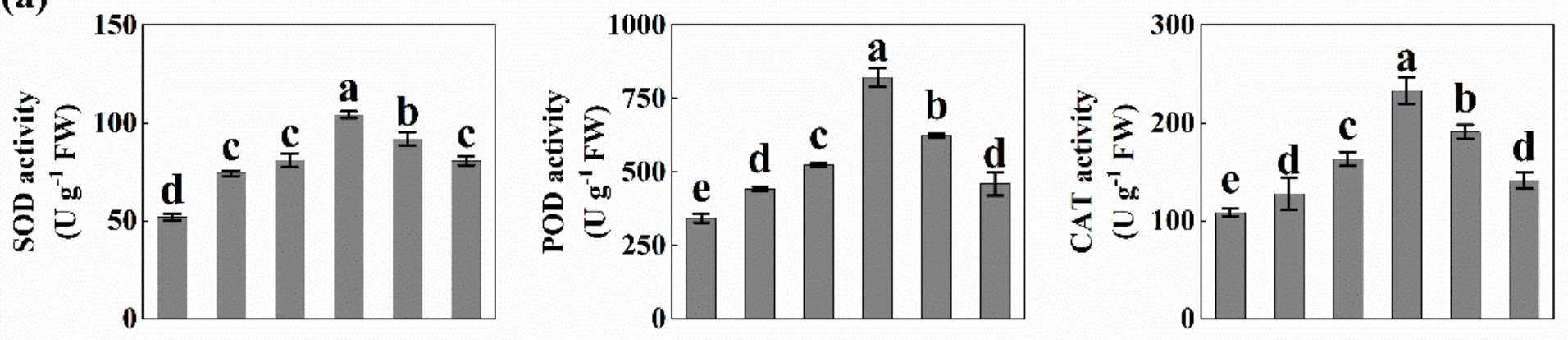

(b)
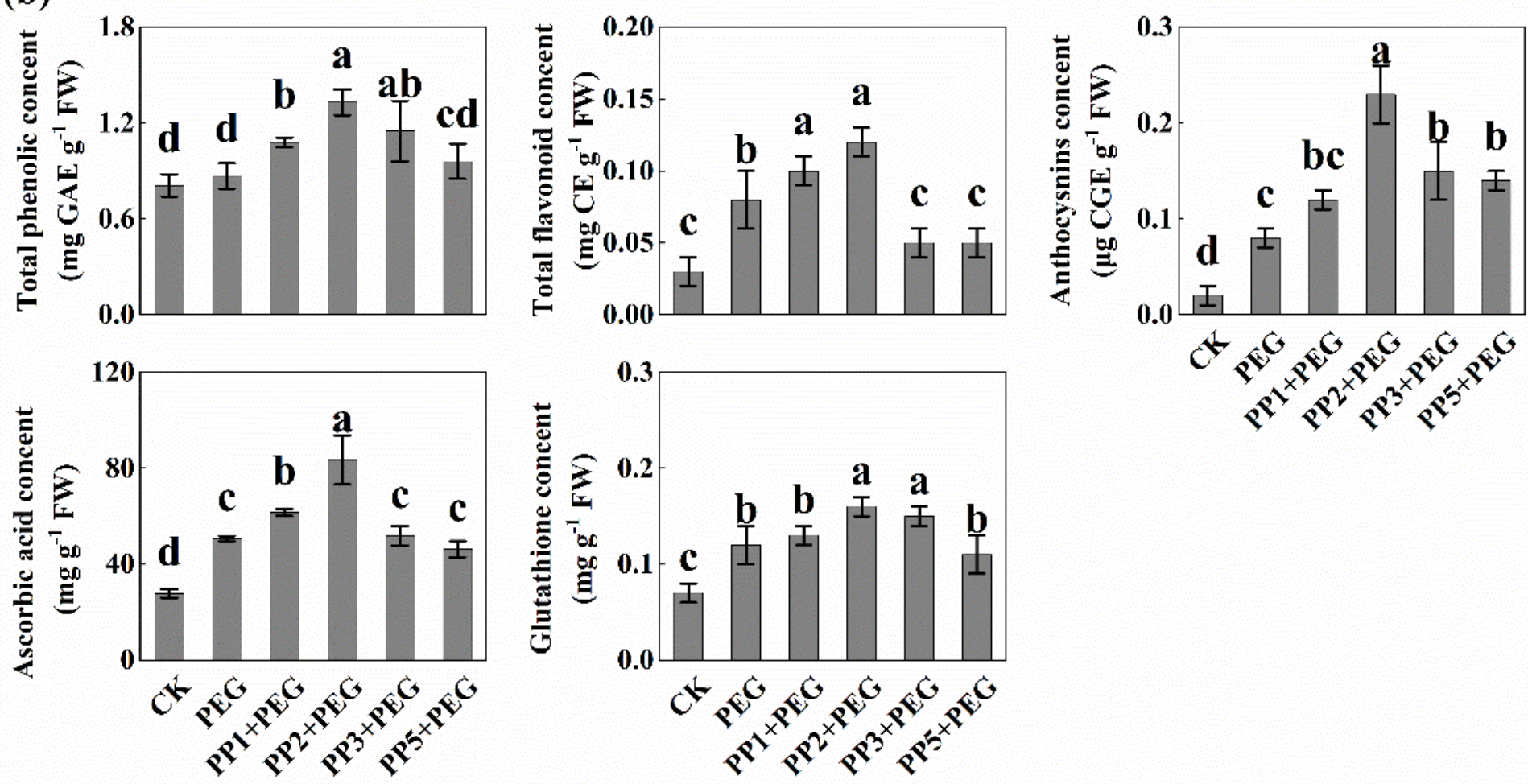

Figure 5

Effects of PP priming on the (a) superoxide activity, peroxidase activity, and catalase activity; (b) total phenolic, flavonoid, anthocyanin, ascorbic acid, and glutathione contents of tomato seedling under drought stress. Different letters indicate a significant difference at $P<0.05$. 
(a)

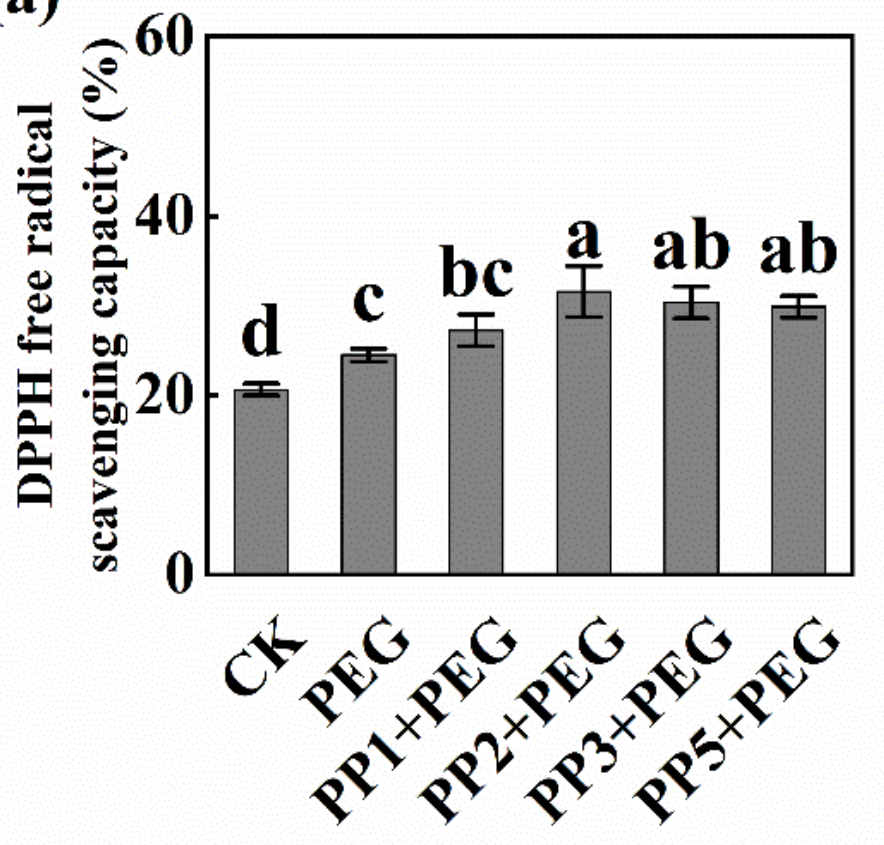

(b)

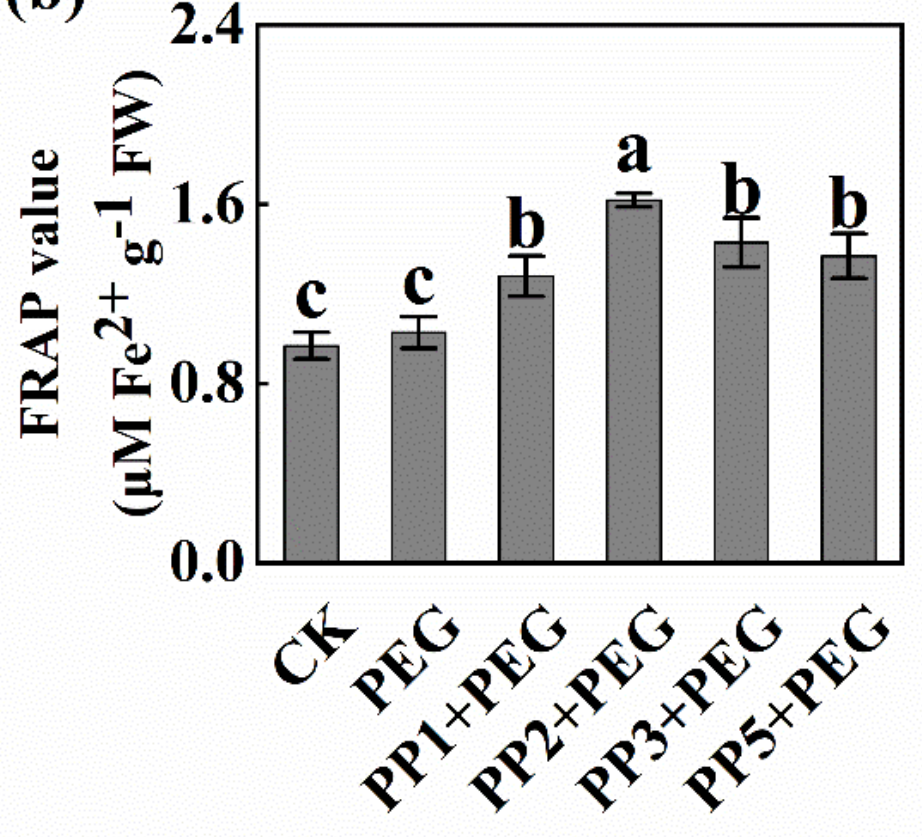

Figure 6

Effects of PP priming on the DPPH free radical scavenging capacity (a) and FRAP value (b) of tomato seedling under drought stress. Different letters indicate a significant difference at $P<0.05$. 
(a)

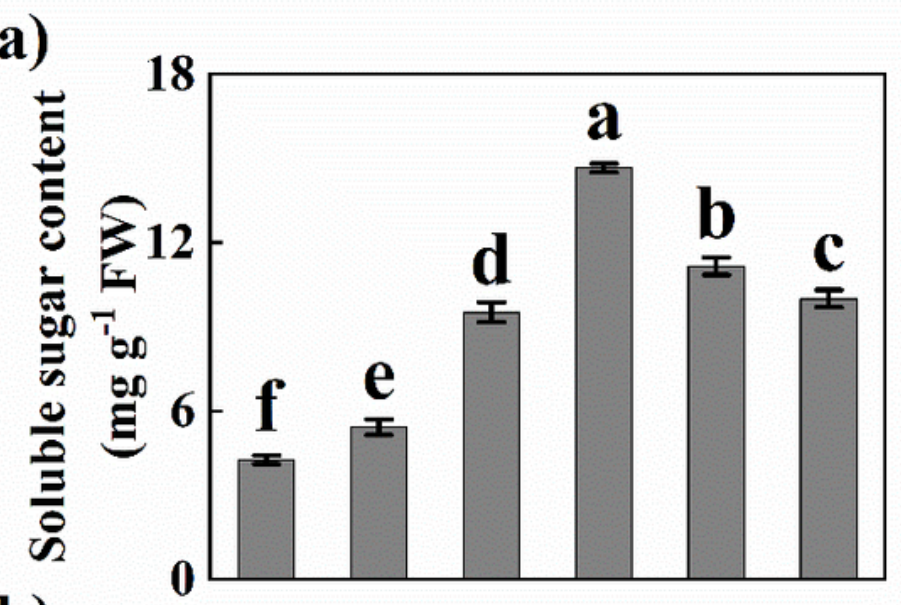

(b)
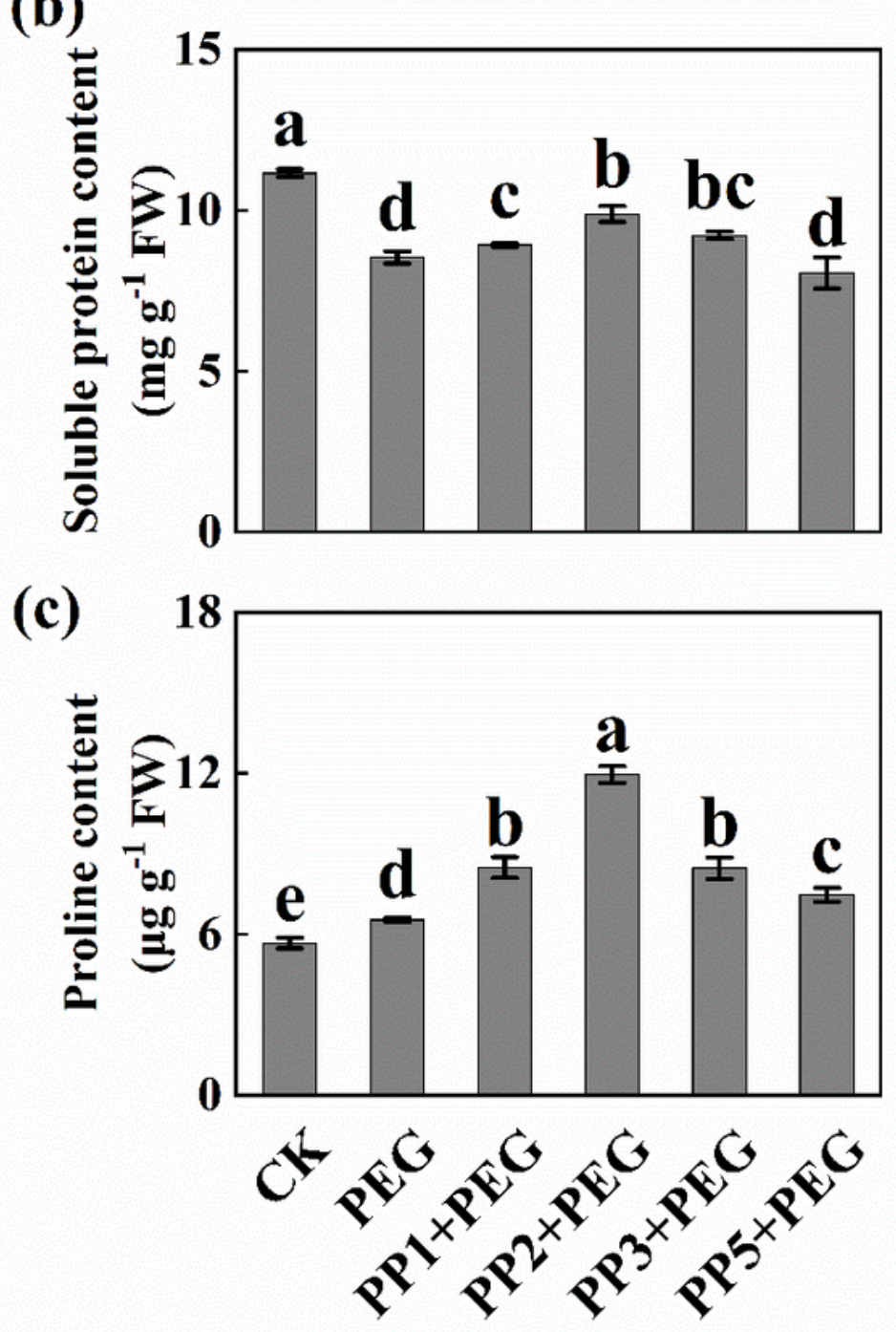

Figure 7

Effects of PP priming on the soluble sugar (a), soluble protein (b), and proline (c) content of tomato seedling under drought stress. Different letters indicate a significant difference at $P<0.05$. 


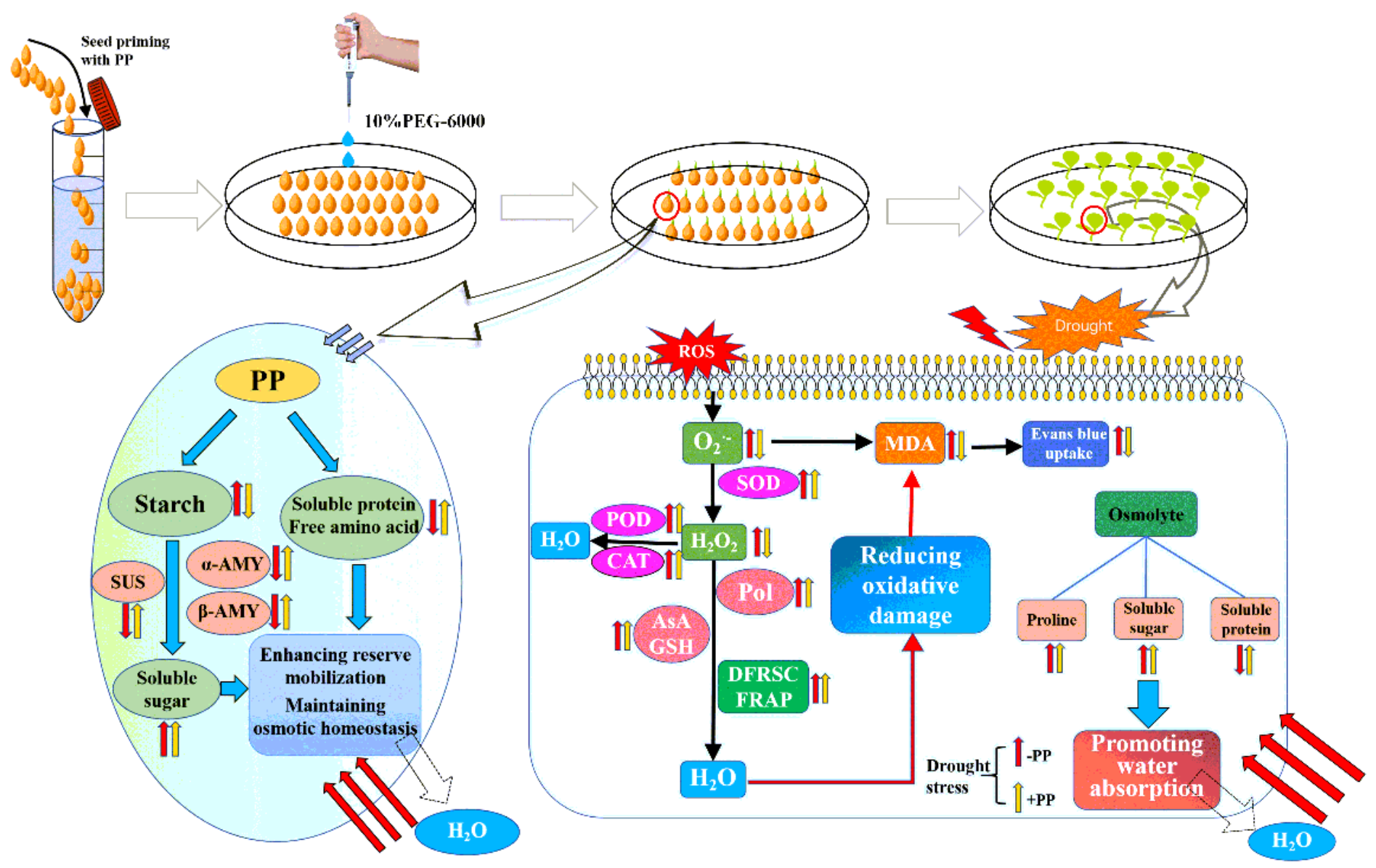

\section{Figure 8}

Functional mechanism of seed priming with PP of enhanced tomato seed reserve mobilization, osmotic adjustment, and antioxidant responses of tomato seedlings under drought stress. The upward and downward arrows indicate the positive and negative effect, respectively. a-AMY, a-amylase activity; $\beta$ AMY, $\beta$-amylase activity; SUS, sucrose synthase activity; SOD, Superoxide dismutase activity; POD, Peroxidase activity; CAT, Catalase activity; Pol, phenolic content; AsA, ascorbate content; GSH, glutathione content; $\mathrm{H} 2 \mathrm{O} 2$, hydrogen peroxide; $\mathrm{O2} \cdot-$, superoxide content; MDA, malondialdehyde content; DFRSC, DPPH free radical scavenging capacity; FRAP, ferric reducing antioxidant power.

\section{Supplementary Files}

This is a list of supplementary files associated with this preprint. Click to download.

- Supplementaryinformation.docx

- floatimage9.png 